Portland State University

PDXScholar

Economics Faculty Publications and

Presentations

Economics

$12-2015$

\title{
A Geographic View of Expansion Choices by U.S. Firms in China
}

\author{
Rossitza Wooster \\ Portland State University, wooster@pdx.edu \\ David Banis \\ Portland State University, dbanis@pdx.edu \\ Ayesha Khalid \\ University of Oregon
}

Follow this and additional works at: https://pdxscholar.library.pdx.edu/econ_fac

Part of the Economics Commons, and the Geographic Information Sciences Commons Let us know how access to this document benefits you.

\begin{abstract}
Citation Details
Wooster, Rossitza; Banis, David; and Khalid, Ayesha, "A Geographic View of Expansion Choices by U.S. Firms in China" (2015). Economics Faculty Publications and Presentations. 48.

https://pdxscholar.library.pdx.edu/econ_fac/48
\end{abstract}

This Post-Print is brought to you for free and open access. It has been accepted for inclusion in Economics Faculty Publications and Presentations by an authorized administrator of PDXScholar. Please contact us if we can make this document more accessible: pdxscholar@pdx.edu. 


\title{
A Geographic View of Expansion Choices by U.S. Firms in China
}

\author{
Rossitza B. Wooster* \\ Department of Economics \\ Portland State University \\ Portland, Oregon, USA \\ wooster@pdx.edu
}

\author{
David Banis \\ Department of Geography \\ Portland State University \\ Portland, Oregon, USA \\ dbanis@pdx.edu
}

\author{
Ayesha Khalid \\ Department of Economics \\ University of Oregon \\ Eugene, Oregon, USA \\ ayeshak@uoregon.edu
}

Forthcoming: The International Trade Journal

\begin{abstract}
How does geography matter for explaining the location patterns of U.S. companies in China? We combine insights from the literature on economic geography and spatial interdependence in foreign direct investment (FDI) activity, to provide a comparative analysis using both sectoral regression results and maps that illustrate patterns in the data. We use a unique sample of publicly traded U.S. firms who announced expansion of operations into China between 1980 and 2005. Regression results show that relative to the tertiary sector, firm characteristics matter more for primary sector firms, whereas province characteristics matter more for secondary sector firms. Additionally, our GIS analysis reveals a high level of locational concentration and differences in provincial characteristics over time. Overall, we find that combining GIS with FDI data that contains geographic attributes can provide a richer picture of economic activity that is highly accessible to both academics and practitioners.
\end{abstract}

Key Words: Economic Geography; Foreign Direct Investment; Geographic Information Systems; China.

\footnotetext{
* Address correspondence to Rossitza B. Wooster, Department of Economics, Portland State University, P.O. Box 751, Portland, OR 97207. Email: wooster@pdx.edu. Wooster gratefully acknowledges financial support from the Dean of the College of Liberal Arts and Sciences at Portland State University.
} 


\section{Introduction}

Over the past two decades, a growing body of research in economics, primarily in the fields of international trade and foreign direct investment (FDI), has focused on how a country's geography shapes its economic growth and development. Moreover, in the recent economics literature, the main source of new advances in research on when and why geography matters has been the development of new statistical techniques for spatial analysis. For example, the use of spatial econometrics in FDI studies has improved the precision of estimates predicting which factors help determine FDI flows by taking into account the dependency between locations. Similarly, statistical analysis of spatial influences has further developed our understanding of how production networks develop and the emergence of industry clusters over time. However, while econometrics techniques can be readily employed to statistically evaluate the effect of spatial dependence in aggregate FDI flows or even FDI flows at the sectoral level, they are less applicable when data is measured at the firm-level.

More importantly, due to the averaging across observations that is necessary to produce estimated coefficients for the explanatory variables in a regression specification, important information at the individual level may be lost. For example, if the predicted relationship between GDP and FDI is positive, it is quite possible that a sample can contain observations that strongly support this prediction but also ones that, equally strongly, do not (Asiedu, 2002; Blonigen and Wang, 2005). Consequently, in a multivariate analysis combining these observations, the overall estimate for the coefficient of GDP may be insignificant leading to a seemingly erroneous conclusion that the variable is not a statistically important determinant of FDI. One way of dealing with such cases, of course, is to carefully select covariates based on theory and use various 
statistical tools to explore the data for outliers as well as minimize the possibility of a nonrepresentative sample.

A complementary approach for improving model selection that is gaining increasing popularity is to use Geographic Information Systems (GIS) to visualize the data. Maps of economic activity across geographically related areas enhance research by highlighting regional variation among the variables in a model in a highly accessible way. The objective of this paper is to employ a standard regression analysis of factors that are important to FDI by U.S. firms in China by economic sector and then compare the resulting insights with those that we obtain using maps of economic determinants of FDI by province. We use a unique sample of publicly traded U.S. firms that have announced expansion of operations into China between 1980 and 2005. Due to the fact that observations in our sample are at the firm level, we cannot employ spatial econometric techniques to control for spatial dependence in FDI flows but our GIS analysis allows us to further explore key province characteristics that traditionally serve as determinants of FDI. We map our firm-level data by province and relate these observations to provincial characteristics such as GDP per capita, wages, FDI per capita and infrastructure values. We find both expected and unexpected patterns through our GIS analysis which allows us to visualize patterns in the data and, in this way, contribute to the literature on locational choices by multinational enterprises.

The rest of the paper is structured as follows. Section II reviews the FDI literature that incorporates spatial analysis and GIS. We discuss our sample construction methodology in Section III. Here we summarize the data for both the U.S. companies in our sample as well as the provincelevel characteristics we employ. Our research methodology is outlined in Section IV. We discuss our regression results and maps in section V. Section VI concludes with some directions for future work. 


\section{An Interdisciplinary Literature Review}

\section{A. FDI and Spatial Interdependence}

In the new millennium, the relevance of geography to the patterns of economic activity has increasingly motivated the use of spatial econometrics to capture how data for neighboring territories may be interrelated (Fingleton, 2001). Because FDI is a spatially varying activity, newer contributions to the traditional literature on the determinants of FDI (such as large markets, access to resources and low-cost sourcing) have been largely the result of examining the spatial interdependence of FDI flows (see for example Blanco, 2012; Blonigen et al., 2007; Coughlin and Segev, 2000). Additionally, theories conceptualized to explain FDI location have attributed the locational patterns to factors such as agglomeration economies, institutions and comparative advantage (Tan and Meyer, 2011). Agglomeration economies indicate the self-reinforcing mechanism of FDI. Factors such as scale economies, specialized labor (Audretsch and Feldman, 1996), and knowledge flows (Liefner \& Zeng, 2008) can create positive feedback loops (Storper, 2000) that can result in high concentration levels of FDI in some locations. Institutions also influence FDI patterns, either through minimizing transaction costs or regional integration agreements. Related to cost minimization are factors that give rise to comparative advantage such as labor costs and transportation costs, among others.

While empirical work to investigate the determinants of FDI has traditionally used gravity models, one of the first studies to incorporate spatial econometrics is Coughlin and Segev (2000). The authors use data of U.S. FDI across provinces in China and find that economic size, labor productivity and coastal location encourage FDI at the provincial level, while higher wages and illiteracy serve as deterrents. Other studies on China have also shown the significance of spatial 
interdependence in FDI patterns at both the provincial level (Cheung and Lin, 2004) and city level (Madariaga and Poncet, 2007).

More recently, Blonigen et al. (2007) explore how FDI in a country depends on the FDI activity in neighboring countries. The authors use spatially weighted FDI as well as market potential as two variables that help to better identify the mechanisms at play behind firm's decisions to expand operations in different regions. For example, the authors show that the surrounding market potential of a given location (i.e. the GDP or GDP per capita of neighboring countries) plays an important role in encouraging FDI by firms whose goal is to identify locations that can serve as export platforms. Similarly, FDI flows are also shown to concentrate where supplier networks span neighboring locations giving rise to agglomeration effects. With respect to the spatially weighted FDI variable, setting up operations in a given location can be viewed as either a substitute for, or as a complement to, locating operations in a neighboring country. The authors show that FDI in a given location is a substitute for that in a neighboring jurisdiction when firms engage in export platform or vertical FDI. In contrast, higher FDI levels in neighboring countries are a complement to locating in a given country for production that is vertically fragmented across regions and therefore benefits from agglomeration effects.

An important finding in Blonigen et al. (2007) concerns the degree of coefficient bias in the regression models used in FDI studies, due to the omission of spatial interactions. They examine whether the estimated spatial interactions in FDI behavior are robust across samples and specifications using a modified gravity model in log-linear form which includes GDP, population, distances between countries, trade frictions, skilled labor endowment, market potential, and a spatially lagged dependent variable. Using disaggregated industry-level data of US outbound FDI to forty host countries between 1983 and 1998, the authors show that spatial interdependence is 
significant; however, omitted variable bias from not incorporating spatial interdependence is small and insignificant. This result is particularly encouraging with respect to analyses of firm-level FDI activity where spatial lag construction is not feasible.

Specifically, although spatial econometrics offers techniques to analyze spatial interdependence, it is most readily applicable to analyses using aggregate data on FDI flows at the country or province level. On the other hand, using spatial autoregressive and spatial error corrections with firm-level data is not feasible as it would require a firm-to-firm matching of FDI across neighboring locations. In addition, there are some geographic characteristics whose influence is not captured by regression analysis. GIS is a computer-based database that is used for acquiring, storing, transforming, analyzing and demonstrating geographically referenced data. The potential advantage of GIS is the spatial analysis of the data. It allows for the examination of spatial relationships between economic indicators and physical geographic characteristics.

\section{B. Application of GIS to the Analysis of FDI Patterns}

With respect to applications of GIS to economic analyses, some of the main domains where GIS is currently being utilized are land use, natural resources, environment analysis, infrastructure management, transportation planning, health, and economic development (Taupier and Willis, 1994). Within the field of international economics, the New Economic Geography theories pioneered by Krugman (1991) emphasize that a firm's choice of where to locate production is critically influenced by access to markets for final goods and input suppliers. These prerequisites for economic activity in a given location are naturally linked to geography and agglomeration is primarily attributed to factors such as increasing returns to scale, imperfect competition and transport costs rather than the physical geography of locations. Though this line of research often considers physical geographical characteristics of countries such as common language, bilateral 
trade partner, colonial history, and common border, but these variables do not lend themselves to visual representation using maps.

An important example of research that links economic indicators with physical geographical features is Gallup, Sachs and Mellinger (1999). In particular, the authors assess the influence of geographic features such as weather conditions and coastal access on economic development in terms of per capita GDP. They use global and regional data from geographic information systems (GIS) for climate zones, population, navigable rivers, and per capita GDP for 152 countries, with more than one million inhabitants in 1995. The paper presents evidence on geographic distribution of GDP per capita, GDP density, and population density. The results show that per capita GDP and population density is high in temperate regions, with GDP density being the highest in these regions. Moreover, countries in temperate zone generate about 50 percent of the economic output in the world, even though they only represent 8 percent of inhabited land. This implies that regions that are tropical, dry, and sub-tropical are relatively poorer and less developed than temperate regions.

In the analysis of FDI activity, there are a handful of papers that apply GIS to capture the relationships between physical geography and FDI patterns. For example, Buckley \& Ghauri (2004) review the international business literature to explore how locational strategies of multinational enterprises (MNEs) are related to economic geography and globalization. In this study, globalization is viewed in terms of conflict between markets and economic management. The literature shows that evolving locational policies of MNEs have resulted in fine division of firm activities, thereby deepening the spatial division of labor. Economic geography plays a part in the structure of local labor markets, which are an important determinant of FDI. According to the literature, economic geography is becoming more relevant in our effort to understand the 
important developments in international business. The authors suggest that there is a need to examine the spatial interdependence of FDI, spatial-temporal patterns of MNEs, and the geographical factors that determine location strategies. Moreover, physical geographical features need to be taken into account in the analysis of FDI and MNE strategies.

In a related vein, Huang \& Wei (2010) examine the spatial and temporal clusters, and location determinants of FDI in China. They analyze the data using spatial statistics of Moron's I and Getis-Ord G, GIS, and geographically weighted regressions. The spatial statistics determine whether spatial autocorrelation exists in FDI patterns within China, and detect concentrations of high and low FDI levels. The data used in the study combine locational characteristics data with GIS spatial files. The locational characteristics data including FDI, FDI per capita, GDP, GDP per capita, average annual wage cost, railway length, land area is obtained for 27 Chinese provinces and four municipalities for the years 1989 through 2007. Regression results show that all Chinese provinces have attracted FDI, but it is unevenly distributed: FDI is generally concentrated in coastal regions, Special Economic Zones, and provincial capitals. Though the share of FDI has increased in central China, the eastern region still attracts more FDI. Also, FDI has shown clustering of spatial autocorrelation and high concentration levels at provincial level since 2002. Regression results reveal that agglomeration, institutions, and infrastructure have a positive and significant impact on FDI.

In another study, Huang \& Wei (2014) investigate the impact of institutions, urban structure and accessibility on the location of FDI in Wuhan, China. The authors also map the change in the behavior of FDI within Wuhan since 1990 to analyze the success of relevant policies. For this purpose, they use spatial statistics and GIS, based on firm characteristics data from the 2008 census. Both local and global spatial statistics, Moron's I and Getis-Ord G, are used to 
examine spatial patterns of FDI. Moreover, a logistic model is combined with geographically weighted regressions to examine factors that determine the location of FDI. Spatial statistics reveal that there has been a pattern of FDI clustering of positive spatial autocorrelation since 2006. Furthermore, the important factors that determine FDI location within Wuhan appear to be institutions, urban structure, and accessibility. The results also show that FDI is centralized on the Wuhan Economic and Technological Development Zone since 2006.

Finally, Li \& Wei (2010) examine the spatial and temporal pattern of regional inequality in China from 1987 to 2007, using GIS and statistical methods. The study uses a multi-scale, multilevel, and multi-mechanisms framework. The data for this study includes per capita GDP, per capita FDI, share of state-owned enterprise, education, population growth for 27 provinces and 4 municipalities of China, and GIS shapefile. ${ }^{1}$ The empirical framework employs multilevel regression modeling along with inequality statistics based on coefficient of variation (CV), Gini coefficient, and Theil index. The inequality statistics of CV, Gini, and Theil show that interprovincial inequality in 2007 was lower than that in 1978, whereas the interregional inequality in 2007 was higher than in 1978. Interregional inequality increased over time due to better economic performance in the eastern region relative to the central and western regions. Moreover, due to geography and policy, the eastern region accounted for more than 75 percent of FDI since 1978. Consequently, this led to significant variation in per capita GDP across regions and provinces. In particular, the contribution of the eastern region to total GDP in China was more than 50 percent suggesting that the main factor causing regional disparities was the uneven distribution FDI among the three regions. As we show in Section V below, location densities for our sample

\footnotetext{
${ }^{1}$ Shapefiles store geospatial vector data which pertain to the physical geographic attributes of locations and allow for analyses of how physical and human activities vary across space.
} 
of U.S. companies also exhibit a strongly uneven distribution. We next turn to a description of this sample and the methodology we used to collect the data.

\section{Sample Construction and Data}

In this paper we use a unique, hand-collected sample of U.S. firms with business presence in China. We begin sample construction by searching the "Directory of American Firms Operating in Foreign Countries," from Uniworld Business Publications, Inc. Names of firms with business operations in China from 1980 to 2005 were obtained from the various editions of the directories. We next determine which firms in the initial sample are publicly traded, and delete all non-publicly traded firms. We also delete all financial firms, because systematic differences in the nature of their assets render cross-sectional comparisons with industrial firms inappropriate for our study. Finally, we delete firms with missing book value of assets on Compustat, leaving a usable sample of 404 firms. We continue sample construction by searching the Lexis-Nexis Academic Universe database for specific announcements of these firms' activities in China from 1980-2005. We search for all announcements of unique investments in China by each sample firm, and classify each of these investments according to whether they are a joint venture, wholly owned subsidiary, acquisition of an existing company, representative office, or large sales/service contract. The final sample of useable observations includes 368 publicly traded companies with announcements of expansion into China between 1980 and 2005.

We complement data on when, where and how U.S. firms expanded in China with provincial characteristics available from the China Data Online Database. The literature outlines a number of locational variables that influence the timing and location of investment. Shapiro, Tang, and Ma (2007) find that location choice for equity joint ventures is significantly determined by wages, FDI stock, education, and presence of special economic zones. Additional studies on 
locational impact of investment flows include proximity to markets and suppliers (Amiti and Javorcki, 2008), labor quality, economic zones, and distance (Gao, 2005), and patent certification volume, share of state-owned business, GDP, wage, and road density (Kawai, 2009). We utilize the following provincial characteristics in our maps and regression analysis. SEZ is a dummy variable denoting whether the province had a Special Economic Zone at the time of investment, WAGES is average province wages scaled by the national average wages. GDPCAP is provincial gross domestic product per capita, and HIGHWAY measures provincial highway density.

Though not a motive for FDI, another important variable for explaining the geographical distribution of FDI is agglomeration economies (i.e. clustering). When agglomeration economies are present, new investors mimic past investment decisions by other investors in choosing where to invest. By locating next to other firms, they benefit from positive spillovers from investors already in place. The common sources for these positive externalities are knowledge spillovers, specialized labor, and intermediate inputs. Variables related to agglomeration effects include the host country (or, in our case, province) stock of FDI. A one year lagged value of the stock of FDI in a given location is customary to use as a proxy for the extent of agglomeration prior to the event of investment.

\section{Research Methodology}

We construct a model that allows us to control for firm characteristics and evaluate how province characteristics matter for U.S. firms from the primary, secondary and tertiary sectors who have expanded in China between 1980 and 2005. Specifically, consider a sample of N firms where each firm $i$ belongs to one of three mutually exclusive sectors of the economy. We assume that the attractiveness of a province as a destination for FDI is a function of firm, industry and province level characteristics and we apply an unordered discrete choice model to evaluate how such 
characteristics affect the likelihood of observing firms from different sectors making investments over time. Specifically, we posit that unobserved profit for firm $i$ from sector $j$ is given by:

$$
\pi_{i j}^{*}=X_{i} \beta_{j}+\varepsilon_{i j}, j=1 \ldots M, i=1 \ldots N
$$

where $X$ is a matrix of firm, industry and province covariates which, together with the coefficient vectors $\beta_{j}$, comprise the deterministic component in equation (1). If sector $\mathrm{j}$ is observed, then the firms and province characteristics combine to produce the highest $\pi_{i j}^{*}$ which means that the observable dependent variable of what sector is observed at a given location in a given year is linked with its latent counterpart $\pi_{i j}^{*}$ via:

$$
\text { SECTOR }_{i}=\left\{\begin{array}{c}
j \text { if } \pi_{i j}^{*}=\max \left(\pi_{i 1}^{*}, \pi_{i 2}^{*}, \pi_{i 3}^{*}\right) \\
0 \text { otherwise }
\end{array}\right.
$$

The probability of observing sector $j$ can then be written as:

$$
\begin{aligned}
\operatorname{Pr}\left[\operatorname{SECTOR}_{i}\right. & \left.=j \mid X_{i}\right]=\operatorname{Pr}\left[\pi_{i j}^{*}>\pi_{i(j-1)}^{*}, \ldots, \pi_{i j}^{*}>\pi_{i(j+1)}^{*}\right] \\
& =\operatorname{Pr}\left[\begin{array}{c}
\varepsilon_{i j}-\varepsilon_{i(j-1)}>X_{i}\left(\beta_{(j-1)}-\beta_{j}\right) \\
\ldots, \varepsilon_{i j}-\varepsilon_{i(j+1)}>X_{i}\left(\beta_{(j+1)}-\beta_{j}\right)
\end{array}\right]
\end{aligned}
$$

The explanatory variables in the $X$ matrix of covariates include both firm and province characteristics and we describe these as follows. Firm Size is the natural log of book value of assets for a company in our sample and allows us to control for company size which is an important determinant of firms' ability to compete on international markets. Firm Domestic Market Share is firm sales divided by 4-digit industry sales and this variable allows us to capture whether being an industry leader domestically is equally important for firms from different sectors when it comes to establishing presence in foreign countries. The International experiences dummy is equal to one if the firm has operations is more than one geographic segment and is thus a proxy experience with doing business in foreign countries. The Product market diversification dummy is equal to one if firm has more than one business segment and allows us to capture another type of experience, 
namely, the organizational learning that accrues when a companies have a broad scope of operations across different business segments.

The characteristics of the location where a sample firm establishes its first operation in China are captured using province characteristics that serve as the traditional determinants of FDI. Lag Province FDI is the natural log of total province FDI in the year preceding the observed expansion by a U.S. company in that province (in US dollars). This is our measure of possible agglomeration effects which occur when companies locate near other companies to take advantage of informational, production, and business network synergies (Head and Reis, 1996; Chen and Kwan, 2000). GDP per capita index is a measure of market size as determinant of FDI. Provincial highway density is the total number of road and railways in a province scaled by province population. We use this as a measure of province infrastructure as a determinant of FDI finally Provincial average wages Index is our measure of the relative cost of production in a given province relative to other locations in China. We note that the GDP per capita and WAGES variables are measured as an index because China Data Online reports these in Yuan while FDI per capita is reported in US dollars. Using the index avoids the need to convert these variables using an exchange rate. We provide descriptive statistics for the explanatory variables in Table 1. In Table 2, we also provide a ranking of provinces according to the size of FDI flows for the full sample (1980-2005) as well as three subsamples we use in our GIS analysis below.

We estimate equation (3) as a multinomial probit with the service sector as the baseline although results with other sectors as a baseline are available upon request. Regarding the estimation procedure, the advantage of the multinomial probit framework over other ordered choice models is that the multinomial model prevents us from formulating an a priori ranking on the patterns of expansion and avoids the independence of irrelevant alternatives assumption. We 
note that our estimation does not model for spatial lag dependence by either including a spatially weighted FDI (spatial lag) or by estimating a spatial lag model. As noted before, because our sample is comprised of firm-level data, spatial correction in our estimation is not feasible. Instead, we complement the regression analysis with GIS methods to create a series of maps that serve as a visual depiction of the location characteristics corresponding to firms' expansion choices. GIS helps us analyze spatial interdependence in data with geographic attributes and for the purposes of our analysis, we use the ArcGIS platform from ESRI to create maps showing the province characteristics associated with the locations where U.S. firms choose to set up operations in China. ${ }^{2}$

\section{Results and Discussion}

\section{A. Regression Results}

Results from the estimation of equation (3) are presented in Table 3. The dependent variable, SECTOR, equals 1 for firms from natural resources and mining industries (primary sector), 2 for manufacturing companies (secondary sector) and 3 for companies in the information, professional business, and other services industries (tertiary sector). The regression uses 368 observations of unique companies announcing first-time investments in China over the period 1980-2005. Because our goal is to examine whether firm- and province-level characteristics differ in their importance for firms from each of these three sectors, we only use the very first instance a company locates operations in China and this choice of location is perhaps most indicative of how sensitive firms are to the attributes of different provinces. By comparison, announcements of expansion subsequent to the first one are less informative of the main characteristics of a company's location choice as these repeat investments are benefitting from the experience a company acquires through its first expansion.

\footnotetext{
${ }^{2}$ For an overview of the ArcGIS platform see: http://www.esri.com/software/arcgis.
} 
Overall the results in Table 3 suggest that there are some interesting differences between firms in the primary, secondary, and tertiary sectors with respect to the firm and province characteristics that correlate with the choice of expanding operations into China between 1980 and 2005. First, relative to firms from service sector industries, the probability that primary sector companies are also domestic market share leaders is significantly less likely. In contrast, primary sector firms are significantly more likely to have presence in one or more geographic locations relative to service sector firms. For primary sector companies, whose business is primarily in the agricultural, resources and mining industries, locating in proximity to where natural resources are abundant is of primary concern.

For service firms, on the other hand, location is less predetermined by the availability of natural resources and thus other province characteristics such as market size (as measured by the GDP/capita proxy), infrastructure, and relative cost of production (as measured by the relative province wage index) emerge as important when choosing where to locate operations. In fact, wages are significantly less likely to be a factor of importance for primary sector companies when compared to service sector companies for whom labor quality is of significantly higher importance (negative and significant coefficient on Provincial average wages index). We note, however, that the insignificant coefficients on lagged FDI per capita for both primary and secondary sectors do not indicate that agglomeration forces have an insignificant effect overall. Rather they suggest that for firms in these sectors agglomeration forces are not significantly stronger compared to firms in the tertiary sector. Significant clustering of firms in given locations (Beijing, Shanghai and Guangdong) does indeed exist in our sample which we explore further in our GIS analysis below.

When we examine the secondary sector, the overall impression is that firm-level variables are much less prominent in their influence compared to the primary sector and province level 
variables begin to gain higher significance. For example, the only firm-level variable that acquires significance is the Product market diversification dummy which is negative suggesting that relative to service sector firms, manufacturing firms are significantly less likely to have operations spanning multiple business segments. More importantly, for secondary sector firms, the probability that market size (measured by GDP/capita) and infrastructure (measured by density of road and railway lines in a province scaled by population) correlate with frequency of manufacturing investments is significantly lower when compared with tertiary sector firms. This is consistent with the expectation that firms in service industries are much more reliant on market size and infrastructure for future sales. Manufacturing firms on the other hand may also rely on these characteristics but to a much lesser extent. Throughout most of the 1980s and early 1990s, Chinese authorities required that foreign companies export half of the produced output in an effort to generate hard currency for the country. As many companies located in China to create export platforms in government-authorized special economic zones, the infrastructure was less of an issue and additionally, requirement that most operations take the form of joint ventures meant U.S. companies could partially benefit from the business networks of local partners (Chantasasawat $e t$ al., 2010).

Despite the insights discussed above, the results from the simple multinomial probit model above are averages over a very diverse set of provinces. Furthermore, due to the relatively small number of observations (total unique companies in the sample is 368), many covariates that may offer additional insights cannot be included as the regression model begins to encounter convergence issues. As such, the multinomial probit in Table 3 is fairly limited. But the tools that are available to us from the application of GIS mapping to the data provide an alternative way to 
analyze patterns of association between province characteristics and location choices by U.S. companies between 1980 and 2005. We discuss the GIS analysis results in more detail below.

\section{B. GIS Analysis}

As a starting point of our GIS analysis, we begin with a visual representation of the frequency with which the totality of observations of U.S. companies in China from the beginning of record keeping up to and including 2012 (total of 7,250 records at the time of data extraction) compares to the sample of U.S. publically traded companies announcing operations in China between 1980 and 2005 (total of 840 records). For illustration purposes we first provide an administrative map of China in Figure 1 which shows the provinces clearly labeled but we remove labels in the figures that follow to focus attention on the patterns across regions.

In Figure 2, we illustrate the density of records by province and we note several important observations. First, the population of companies (both private and public) that account for all China records in the Uniworld database, show a remarkably similar density pattern when compared to that obtained by mapping the subsample of 840 records that correspond to expansion announcements by publicly traded companies from this population of companies. Specifically, we note that Beijing, Shanghai and Guangdong are the locations with the highest density of records in both the Uniworld database and the sample we use in this analysis. This is not surprising as these three locations comprise the political, financial and commercial centers in China and the concentration of U.S. companies establishing operations in these locations is consistent with findings in previous research which highlight the importance of positive agglomeration externalities (Tan and Meyer, 2011; Taube and Ögütçü, 2002).

To investigate this pattern further, we use our sample of 840 observations of companies announcing expansion into China to explore the patters over time. In particular, we split the 1980- 
2005 sample in three periods in Figure 3. The early period coving 1980-1992 encompasses a stage in China's policy toward FDI where the only government sanctioned mode of investment was through joint ventures and restrictions related to exports and currency repatriation were commonplace. Not surprisingly, only 80 of the 368 unique companies in our regression sample announced their first investment in China between 1980 and 1992. In contrast, the boom in investment that characterized the early 1990s was encouraged by a handful of China-related and international events. First, in 1992, China relaxed its FDI rules and, for the first time, officially allowed foreign companies to set up wholly owned operations. This move by the Chinese government was partially a recognition that for the country to attract FDI, they need to be competitive in terms of their legal and business framework with other emerging regions in the world that were competing for the capital that foreign companies can potentially invest in their countries. Specifically, the collapse of the former Soviet Union created 25 newly independent countries each of which had significant interest in attracting FDI from western companies (Paul and Wooster, 2008).

Additionally, Figure 3 shows the overall pattern of FDI in China (i.e. not just U.S. FDI, but the volume of all FDI inflows from all western and non-western countries measured in U.S. dollars). In the early time period, the ratio of FDI per capita percentage change to average percentage change is the lowest for Xinjiang Uyghar, Gansu, Qinghai, Ningxia Hui, Shaanxi, Beijing, Yunnan, Guizhou, Hunan, Guangxi Zhuang, Guandong and Fujian. The highest change was in Shanxi, Shandong and Jiansu. In the middle period, Heilongjiang changed from being a relatively high ratio to a relatively low ratio. Hebei, on the other hand, advanced from a relatively high FDI per capita intensity to being the highest ratio. Similarly, Beijing and Ningxia Hui, also 
had the highest ratio of FDI per capita percentage change to average percentage change in this period, from having the lowest ratio in the previous period.

We note that many of these changes are also observable in the rankings of provinces according to FDI flows presented in Table 2. For example, Fujian and Jiangsu are absent from the rankings in the early period but emerge quite high on the list in the middle period. Specifically, the boom in FDI flows to these provinces is undoubtedly linked to the FDI promotion efforts by Chinese authorities in neighboring Guangdong and Shanghai, respectively. Thus the success of neighboring provinces in attracting FDI provides an underlying structure for FDI flows to emerging locations in the early 1990s such as Fujian and Jiansu (LeSage and Pace, 2009; Elhorst, 2014). Such neighborhood effects are consistent with the "regions learning from each other" theory provided by Buera et al. (2011).

Additionally, the strong self-reinforcing effect of FDI on itself that Cheng and Kwan (2000) document for China and the agglomeration effects identified by Head and Ries (1996) ensure that the success in one province need not be at the expense of its neighboring locales. In the late period, Inner Mongolia, Tibet, Sichuan, Chongqing, Henan, Anhui and Jiangxi had the highest FDI per capita intensity in this period, compared to having the lowest ratio in the middle period. Moreover, Hebei, Beijing, Ningxia Hui and Jiangsu changed from having the highest FDI per capita intensity to having a relatively low or lowest ratio. It is interesting to note that staggering percent increases in FDI in provinces like Inner Mongolia and Tibet is not an indication of massive inflows of FDI in these destinations. Rather, because the levels of FDI in these locations were very low or non-existent), a single company establishing presence can result in an enormous increase. For example, our sample only has one company in Inner Mongolia in the early period and no 
observations in the middle or late period resulting in a 100\% increase in FDI for this province. A similar pattern obtains for Tibet.

With the patterns of FDI discussed above, we next move to the distribution of U.S. companies by economic sector. Figure 4 provides this illustration. We note that for the purposes of showing the sectoral distribution pie charts for the provinces, we have chosen an "exploding map” display which accommodates these and the actual China map is given as an underlying shadow. Figure 4 shows that for the Uniworld sample, Beijing, Shanghai and Guangdong have the highest percent of total records being greater than twenty percent. Even for our hand-collected sample, the highest percent of total records is for Beijing, Shanghai and Guangdong, along with Jiangsu. Furthermore, in our sample, Heilongjiang, Inner Mongolia, Anhui, Hubei and Chongqing have only secondary sectors. Shanxi, Liaoning, Henan have all three sectors. Hunan has primary and secondary sector only. Yunnan and Hainan only have tertiary sectors. Gansu has both secondary and tertiary sector, in almost the same proportion. All other provinces have secondary and tertiary sectors, with a greater proportion of secondary sectors. In the Uniworld sample, Qinghai, Tibet and Hainan have only tertiary sector. Ningxia Hui, Guizhou, Hebei, Tianjin and Anhui have all three sectors.

Because of the diversity of province-specific characteristics, we next turn to examining the pattern of change in three key variables that are traditionally considered determinants of FDI: GDP per capita (as a proxy for market size), wages per capita (as a measure of production costs and/or labor quality), and density of road and railway lines (as a proxy for infrastructure).

Figure 5 shows the widely recognized pattern of income disparity between the coastal and interior provinces. In 1992, GDP per capita was highest in Beijing and Shanghai, being between 5001 and 10,000 yuan per year. The GDP per capita in Beijing and Shanghai further increased to 
being between 15001 and 20,000, in 1999. Moreover, Tianjin also had the same range for GDP per capita in this year. In 2005, Bejing, Tianjin, Jiangsu, Shanghai, Zhejiang and Guangdong, had the highest GDP per capita, being between 20,001 and 50000. Moreover, the value of GDP per capita also increased in Inner Mongolia, Liaoning, Shandong and Fujian. Once again, we note here that similar to the patterns discussed in Figure 3, the enormous percent increase in GDP per capita in Inner Mongolia in the late period is due to the very low base level the province had in the middle period which improved due to the development polices China implemented in the 2000s to increase economic activity in the north east provinces.

Figure 6 provides an illustration of the changes in wages per capita at the provincial level. In 1999, the wages per capita increased in all provinces. In particular, the wages per capita increased in Beijing, Tianjin, Tibet, Zhejiang and Guangdong from being less than 5000 to being between 10,000 and 15000. Moreover, in Shanghai, the wages per capita increased to being between 20,001 and 50,000. In 2005, Beijing, Tianjin, Tibet, Shanghai, Jiangsu, Zhejiang and Guangdong have the highest wages per capita, being between 20,001 and 50,000. Moreover, the wages per capita increased in all other provinces from the value in 1999.

Finally, Figure 7 shows the infrastructure changes over the sample period using the square kilometers of road and rail lines for a given province. Once again, some of the most significant improvement are in the coastal provinces surrounding Beijing and Shanghai and also the commercial powerhouse province of Guangdong. The value for Highway and Rail, in 1992, was the highest in Sichuan, being greater than 1. In 1999, Tianjin also has the highest value for Highway and Rail, along with Beijing. The value also, increased in Guangdong. In 2005, Sichuan also has the highest value along with Beijing and Tianjin. The value also increased in Shandong, Henan, Anhui, Jiangsu and Hubei, and Hainan. 
One benefit of maps is that they can also showcase multivariate associations for variables by location. In Figures 8, 9 and 10, we separately illustrate the relationship between FDI by province and the three variables of interest above. We note that in these maps, we focus on the east coast and central provinces and omit the far west and Inner Mongolia regions due to sparse or no FDI observations over our sample period.

Figure 8 shows that in the early period, both FDI per capita and GDP per capita are the lowest in Sichuan, Guizhou, Yunnan and Anhui. On the other hand, Liaoning, Beijing, Tianjin, Shanghai and Guangdong have the highest value for both FDI per capita and GDP per capita. In Guangxi Zhuang and Shaanxi, FDI per capita is high but GDP per capita is low. Similarly, GDP per capita is high whereas FDI per capita is low in Jilin and Chongqing. In the middle period, FDI per capita and GDP per capita are still lowest in Sichuan and Guizhou. Beijing, Tianjin, Jiangsu, Shanghai and Guangdong continue to have the highest value for both FDI per capita and GDP per capita. In Guangxi Zhuang and Hubei, FDI per capita is high but GDP per capita is low. Again, in Chongqing, GDP per capita is relatively high whereas FDI per capita is relatively low.

Both wages per capita and FDI per capita, in the early period, are the lowest in Sichuan, Guizhou, and Anhui. On the contrary, both FDI per capita and wages per capita are relatively high in Shanghai and Guangdong. In Heilongjiang, Liaoning, Shandong, Beijing, Tianjin, Shaanxi, Chongqing, Zhejiang, Fujian and Hainan, FDI per capita is relatively high though wages per capita is low. In the middle period, FDI per capita and wages per capita are still lowest in Sichuan and Guizhou. Now, FDI per capita and wages per capita are highest in Beijing, Tianjin, Shanghai and Guangdong. FDI per capita is lowest and wages per capita is relatively high in Yunnan. In this case, only in Heilongjiang, FDI per capita is high whereas wages per capita is low. 
Figure 9 illustrates that in the late period, FDI per capita and GDP per capita are lowest in Sichuan, Guizhou, Yunnan and Anhui, as in the early period. Also, in this period, Beijing, Tianjin, Jiangsu, Shanghai, Zhejiang and Guangdong have the highest value for both FDI per capita and GDP per capita. In Jiangxi, Hubei, Hunan and Hainan, FDI per capita is relatively high whereas GDP per capita is relatively low. In this period, GDP per capita continues to be relatively high and FDI per capita is relatively low in Chongqing, along with Jilin and Hebei.

FDI per capita and wages per capita, in the late period, are lowest in Guizhou, Guangxi Zhuang, Henan and Anhui, though in the previous period, FDI per capita was somewhat high in these regions, other than in Guizhou. FDI per capita and wages per capita are highest in Beijing, Tianjin, Jiangsu, Shanghai, Zhejiang and Guangdong. Even in this period, FDI per capita is lowest and wages per capita is relatively high in Yunnan. Now, in Hubei, Jiangxi, and Hainan, FDI per capita is relatively high whereas wages per capita is low.

Figure 10 depicts that in the early period, FDI per capita and transportation is lowest in Sichuan and Yunnan. Both FDI per capita and transportation continues to be the lowest in Sichuan, in the middle and the late period. FDI per capita and transportation, in the early period, is the highest in Beijing, Tianjin, Shanghai, Fujian and Guangdong. The same trend continues in the middle period. However, in the late period, Jiangsu, rather than Fujian has the highest value for FDI per capita and transportation, along with Beijing, Tianjin, Shanghai and Guangdong. Henan has low FDI per capita and relatively high transportation value, in the early as well as the middle period. However, in the late period, Anhui also has low FDI per capita and relatively high transportation value, along with Henan. In the early period, Heilongjiang has low transportation value and relatively high FDI per capita. In the middle period, other than Heilongjiang, Jiangsu also has relatively low transportation value and high FDI per capita. Finally, in the late period, 
Heilongjiang and Liaoning have relatively high FDI per capita and relatively low transportation value.

In summary, our GIS analysis shows some expected, but also some unexpected, patterns. Mapping the locational choices of U.S. companies in China between 1980 and 2005 shows a high concentration in three main locations: Beijing, Shanghai and Guangdong. These provinces are a destination of choice for companies from all three sectors. GDP per capita as well as transportation infrastructure in these locations rank quite high as do FDI flows but wages in these as well as surrounding coastal provinces have also seen the highest increases. Away from these popular locations, some provinces only receive one type of FDI. In our sample, we observe only secondary sector (manufacturing) companies in Heilongjiang, Inner Mongolia, Anhui, Hubei and Chongqing while only tertiary sector (services) companies are observed in Yunnan and Hainan. Finally a positive correlation between FDI flows and traditional determinants of FDI such as GDP/capita, lower wages and better infrastructure does not always obtain. For example, better infrastructure in Anhui and Henan is not associated with higher FDI flows. Similarly, provinces such as Jiangxi, Hubei, Hunan and Hainan have relatively high FDI per capita whereas GDP per capita is relatively low.

\section{Conclusions and Future Work}

We build a dataset of U.S. firms with confirmed investments in China between 1980 and 2005 for the purposes of investigating patterns of location and the importance of province characteristics for firms from the primary, secondary and tertiary sector. We do this in two ways: we estimate a multinomial probit regression and, separately, we create a series of maps using GIS methods for the purposes of visualizing patterns in the data. Our regression results suggest that, relative to service firms in the tertiary sector, firm-level characteristics appear more important for companies 
in the primary sector, while province-level characteristics matter more for manufacturing companies in the secondary sector.

Combining these insights with maps of FDI distribution and province characteristics in China, we note several important patterns. Company location choices are densely concentrated in three main provinces: Beijing, Shanghai, and Guangdong. This result is intuitive in view of the fact that these locations are the main political, financial and commercial centers in China. However, what is also clear is the overwhelming concentration of FDI activity in coastal provinces. Away from the top three locations, FDI flows to provinces in the interior do not always correlate with higher GDP per capita or better infrastructure suggesting motives to expand to these provinces may be less market seeking and more related to availability of resources and supply of intermediate products. While this conclusion is not new, we offer a novel way of viewing the evolution of FDI over time using three periods between the years 1980 and 2005. Here we document how some of the main determinants of FDI, including changes in GDP per capita, wages and infrastructure, correlate with the patterns of FDI we document over the sample period.

An important limitation imposed by the nature of our sample, which uses firm-level data, is that we are unable to apply the techniques from spatial econometrics to study spatial dependence in FDI across provinces in China. However, we find that by combining the traditional regression analysis with GIS methods to create maps that illustrate patterns in the data, we are able to present a richer picture of factors that matter for location choices by U.S. companies. Thus, we posit that in future research, GIS analysis can be a useful and complementary tool to study economic patterns. Additionally, GIS can serve to highlight correlations that can further inform the specification of econometric models. One fruitful avenue for extending the current analysis would be to create maps comparable to those presented here showing the importance of location 
characteristics for U.S. FDI in other regions of the world. Such research would make it possible to visualize cross-regional comparisons of how the traditional determinants of FDI matter for location choices. Finally, data on U.S. FDI flows to China at the aggregate or sectoral level can be employed in future studies to statistically evaluate spatial dependence of U.S. FDI across provinces in China. 


\section{References}

Amiti, M., and Javorcik, B. 2008. Trade Costs and Location of Foreign Firms in China. Journal of Development Economics 85(1-2): 129-149.

Asiedu, E. 2002. On the Determinants of Foreign Direct Investment to Developing Countries: Is Africa Different? World Development 30: 107-119.

Audretsch, D., and Feldman, M. 1996. Innovative Clusters and the Industry Life Cycle. Review of Industrial Organization 11: 253-273.

Blanco, L. 2012. The Spatial Interdependence of FDI in Latin America. World Development 40: 1337-1351.

Blonigen, B. A, Davies, R. B., Waddell, G. R., and Naughton, H. T. 2007. FDI in Space: Spatial Autoregressive Relationships in Foreign Direct Investment. European Economic Review 51: 1303-1325.

Blonigen, B. A., and Wang, M. 2005. Inappropriate Pooling of Wealthy and Poor Countries in Empirical Studies. In T. Moran, E. Graham, and M. Blomström, eds., Does Foreign Direct Investment promote development? pp. 221-244. Washington, DC: Institute for International Economics.

Buckley, P.J., and Ghauri, P. N. 2004. Globalization, Economic Geography, and the Strategy of Multinational Enterprises. Journal of International Business Studies 35: 81-98.

Buera, F., Monge-Naranjo, A., and Primiceri, G. 2011. Learning the Wealth of Nations. Econometrica 79: 1-46.

Chantasasawat, B., Fung, K. C., Iizaka, H., and Siu, A. 2010. FDI Flows to Latin America, East and Southeast Asia and China: Substitutes or Complements? Review of Development Economics 14: 533-46.

Cheng, L.K., and Kwan, Y. 2000. What are the Determinants of the Location of Foreign Direct Investment? The Chinese Experience. Journal of International Economics 51: 379-400.

Cheung K., and Lin, P. 2004. Spillover Effects of FDI on Innovation in China: Evidence from the Provincial Data. China Economic Review 15: 25-44.

Coughlin, C. C., and Segev, E. 2000. Foreign Direct Investment in China: A Spatial Econometric Study. World Economy 23: 1-23.

Elhorst, J.P. 2014. Spatial Econometrics: From Cross-Sectional Data to Spatial Panels. Heidelberg, New York, Dordrecht, London: Springer.

Fingleton, B. 2001. Theoretical Economic Geography and Spatial Econometrics: Dynamic Perspectives. Journal of Economic Geography 1: 201-225.

Gallup, J. L., Sachs, J. D., and Mellinger, A. D. 1999. Geography and Economic Development. International Regional Science Review 22: 179-232.

Gao, T. 2005. Labor Quality and the Location of Foreign Direct Investment: Evidence from China. China Economic Review 16(3): 274-292. 
Head, K., and Ries, J. 1996. Inter-City Competition for Foreign Investment: Static and Dynamic Effects of China's Incentive Areas. Journal of Urban Economics 40: 38-60.

Huang, H., and Wei, Y. H. D. 2010. Spatial-Temporal Patterns and Determinants of Foreign Direct Investment in China. Erdkunde 65: 7-23.

Huang, H., and Wei, Y. H. D. 2014. Intra-Metropolitan Location of Foreign Direct Investment in Wuhan, China: Institution, Urban Structure, and Accessibility. Applied Geography 47: 7888.

Kawai, N. 2009. Locational Strategies of Foreign Investors in China: Evidence from Japanese Manufacturing Multinationals. Global Economic Review 38(2): 117-141.

Krugman, P. R. 1991. Geography and Trade. Cambridge, MA: MIT Press.

LeSage, J. P., and Pace, R. K. 2009. Introduction to Spatial Econometrics. Boca Raton: Taylor \& Francis.

Li, Y., and Wei, Y. H. D. 2010. The Spatial-Temporal Hierarchy of Regional Inequality of China. Applied Geography 30: 303-316.

Liefner, I., and Zeng, G. 2008. Cooperation Patterns of High-Tech Companies in Shanghai and Beijing: Accessing External Knowledge Sources for Innovation Processes. Erdkunde 62: 245-258.

Madariaga, N., and Poncet, S. 2007. FDI in China: Spillovers and Impact on Growth. World Economy 30: 837-862.

Paul, D. L., and Wooster, R. B. 2008. Strategic Investments by U.S. Firms in Transition Economies. Journal of International Business Studies 39: 249-266.

Shapiro, D., Tang, Y., and Ma, C. X. 2007. Mode of Entry and the Regional Distribution of Foreign Direct Investment in China. Journal of Chinese Economic and Business Studies 5(3): 261-277

Storper, M. 2000. Globalization, Localization, and Trade. In G. L. Clark, M. Feldman, and M. Gertler, eds., The Oxford Handbook of Economic Geography, pp. 145-165. Oxford: Oxford University Press.

Tan, D., and Meyer, K. E. 2011. Country-of-Origin and Industry FDI Agglomeration of Foreign Investors in an Emerging Economy. Journal of International Business Studies 42: 504-520.

Taube, M., and Ögütçü, M. 2002. Main Issues on Foreign Investment in China’s Regional Development: Prospects and Policy Challenges. In M. Ögütçü and F. Benois, eds., Foreign Direct Investment in China: Challenges and Prospects for Regional Development. Paris, France: OECD.

Taupier, R., and Willis, E. C. 1994. Geographic Information Systems and Applied Economics: An Initial Discussion of Potential Applications and Contributions. Agricultural and Resource Economics Review 23(2): 140-149. 
Table 1: Descriptive Statistics of Firm and Province Characteristics

\begin{tabular}{r|rrrrr}
\hline & Mean & Median & Std. Dev & Max & Min \\
\hline Firm size & 6.98 & 7.1 & 1.71 & 12.58 & 1.45 \\
Firm domestic market share & 0.18 & 0.09 & 0.23 & 1 & 0.0002 \\
International experiences dummy & 0.38 & 0 & 0.49 & 1 & 0 \\
Product market diversification dummy & 0.42 & 0 & 0.49 & 1 & 0 \\
Lag Province FDI (log) & 4.09 & 4.61 & 1.81 & 6.18 & -3.32 \\
GDP per capita Index & 142.44 & 111.3 & 117.04 & 880.70 & 97.7 \\
Provincial Highway density & 3.35 & 3.23 & 2.93 & 9.78 & 0.01 \\
Provincial average wages Index & 16.77 & 10.98 & 58.6 & 1119.33 & 1 \\
\hline
\end{tabular}


Table 2: Ranking of Chinese Provinces where U.S. Companies Locate by Mean FDI per Capita (Logged)

\begin{tabular}{|c|c|c|c|c|c|c|c|c|}
\hline & \multicolumn{2}{|c|}{ Early Period (1980-1992) } & \multicolumn{2}{|c|}{ Middle Period (1993-1999) } & \multicolumn{2}{|c|}{ Late Period (2000-2005) } & \multicolumn{2}{|c|}{ Full Sample: 1980-2005 } \\
\hline Rank & $\begin{array}{l}\text { Province } \\
\text { Name }\end{array}$ & $\begin{array}{r}\text { Mean of } \\
\ln (\text { FDI/CAP) }\end{array}$ & $\begin{array}{l}\text { Province } \\
\text { Name }\end{array}$ & $\begin{array}{r}\text { Mean of } \\
\ln (\text { FDI/CAP) }\end{array}$ & $\begin{array}{l}\text { Province } \\
\text { Name }\end{array}$ & $\begin{array}{r}\text { Mean of } \\
\ln (\text { FDI/CAP) }\end{array}$ & $\begin{array}{l}\text { Province } \\
\text { Name }\end{array}$ & $\begin{array}{r}\text { Mean of } \\
\ln (\text { FDI/CAP) }\end{array}$ \\
\hline 1 & Beijing & 3.05 & Shanghai & 5.48 & Shanghai & 5.75 & Hainan & 5.03 \\
\hline 2 & Guangdong & 2.37 & Hainan & 5.03 & Tianjin & 5.47 & Shanghai & 4.97 \\
\hline 3 & Shanghai & 2.09 & Fujian & 4.85 & Beijing & 5.17 & Fujian & 4.75 \\
\hline 4 & Tianjin & 1.41 & Guangdong & 4.79 & Guangdong & 4.93 & Beijing & 4.67 \\
\hline 5 & Heilongji & 0.187 & Beijing & 4.63 & Fujian & 4.71 & Guangdong & 4.12 \\
\hline 6 & Zhejiang & 0.12 & Tianjin & 4.62 & Jiangsu & 4.67 & Liaoning & 4.02 \\
\hline 7 & Shandong & -0.26 & Jiangsu & 4.09 & Liaoning & 4.56 & Jiangsu & 3.93 \\
\hline 8 & Hebei & -0.94 & Liaoning & 3.61 & Shandong & 4.55 & Tianjin & 3.50 \\
\hline 9 & Jiangsu & -2.11 & Shandong & 3.37 & Zhejiang & 3.97 & Guangxi & 2.91 \\
\hline 10 & Henan & -2.21 & Zhejiang & 3.32 & Hebei & 2.54 & Shaanxi & 2.54 \\
\hline 11 & Inner Mongolia & -2.58 & Guangxi & 2.91 & Shaanxi & 2.54 & Zhejiang & 2.52 \\
\hline 12 & Sichuan & -2.94 & Heilongji & 2.69 & Heilongji & 2.13 & Hunan & 2.39 \\
\hline 13 & & -3.32 & Hunan & 2.40 & Jilin & 1.97 & Shandong & 2.13 \\
\hline 14 & & & Hebei & 2.10 & Sichuan & 1.95 & Jilin & 1.97 \\
\hline 15 & & & Anhui & 2.08 & Anhui & 1.75 & Jiangxi & 1.92 \\
\hline 16 & & & Jiangxi & 1.92 & & & Anhui & 1.91 \\
\hline 17 & & & Yannan & 1.64 & & & Heilongji & 1.65 \\
\hline 18 & & & Sichuan & 1.40 & & & Yannan & 1.64 \\
\hline 19 & & & Gansu & 0.88 & & & Hebei & 1.27 \\
\hline 20 & & & & & & & Sichuan & 1.08 \\
\hline 21 & & & & & & & Gansu & 0.88 \\
\hline 22 & & & & & & & Henan & -2.58 \\
\hline 23 & & & & & & & Inner Mongolia & -2.94 \\
\hline
\end{tabular}


Table 3: The Importance of Firm and Province Characteristics by Economic Sector

\begin{tabular}{|c|c|c|c|c|}
\hline Firm and Province Characteristics & $\begin{array}{c}\text { Robust } \\
\text { Coefficient }\end{array}$ & $\begin{array}{l}\text { Standard } \\
\text { Error }\end{array}$ & Z-Statistic & $P>Z$ \\
\hline \multicolumn{5}{|l|}{ Primary Sector } \\
\hline Firm size & 0.117 & 0.105 & 1.11 & 0.266 \\
\hline Firm domestic market share & $-2.617^{*}$ & 1.492 & -1.75 & 0.079 \\
\hline International experiences dummy & $0.943 * *$ & 0.438 & 2.15 & 0.031 \\
\hline Product market diversification dummy & 0.522 & 0.518 & 1.01 & 0.314 \\
\hline Lag Province FDI (log) & 0.007 & 0.417 & 0.02 & 0.988 \\
\hline GDP per capita Index & 0.001 & 0.001 & 1.14 & 0.255 \\
\hline Provincial Highway density & -0.098 & 0.115 & -0.86 & 0.392 \\
\hline Provincial average wages Index & $-0.077^{*}$ & 0.042 & -1.81 & 0.07 \\
\hline Constant & $-1.645^{* *}$ & 0.796 & -2.07 & 0.039 \\
\hline \multicolumn{5}{|l|}{ Secondary Sector } \\
\hline Firm size & -0.123 & 0.078 & -1.58 & 0.115 \\
\hline Firm domestic market share & -0.200 & 0.534 & -0.37 & 0.708 \\
\hline International experiences dummy & 0.181 & 0.240 & 0.75 & 0.451 \\
\hline Product market diversification dummy & $0.526 * *$ & 0.249 & 2.11 & 0.035 \\
\hline Lag Province FDI (log) & 0.039 & 0.263 & 0.15 & 0.882 \\
\hline GDP per capita Index & $-0.002 * *$ & 0.001 & -2.26 & 0.024 \\
\hline Provincial Highway density & $-0.185 * * *$ & 0.047 & -3.93 & 0.000 \\
\hline Provincial average wages Index & 0.001 & 0.001 & 0.77 & 0.442 \\
\hline \multirow[b]{2}{*}{ Tertiary Sector } & $2.454 * * *$ & 0.644 & 3.81 & 0.000 \\
\hline & Base 0utcome & & & \\
\hline \multirow{3}{*}{$\begin{array}{r}\text { No. of Observations } \\
\text { Wald chi2(16) } \\
\text { Log pseudolikelihood }\end{array}$} & 322 & & & \\
\hline & 54.4 & & & \\
\hline & -199.056 & & & \\
\hline
\end{tabular}

Note: ${ }^{* *}, * * *$ indicate significance at $10 \%, 5 \%$ and $1 \%$, respectively. 
Figure 1. Administrative Map of China

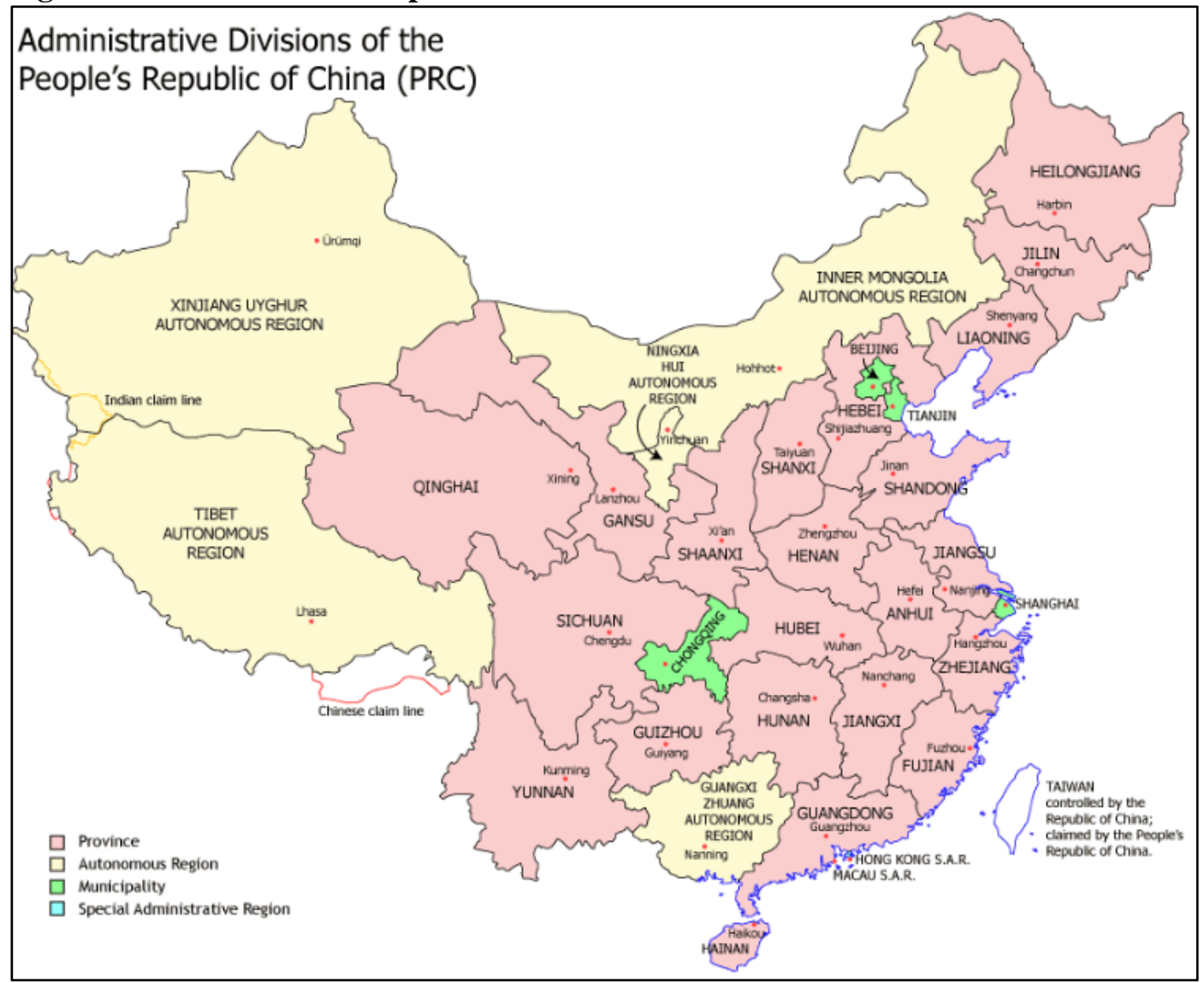

Source: http://en.wikipedia.org/wiki/File:China_administrative.gif)

Figure 2. Density Map: Frequency of Records Comparison

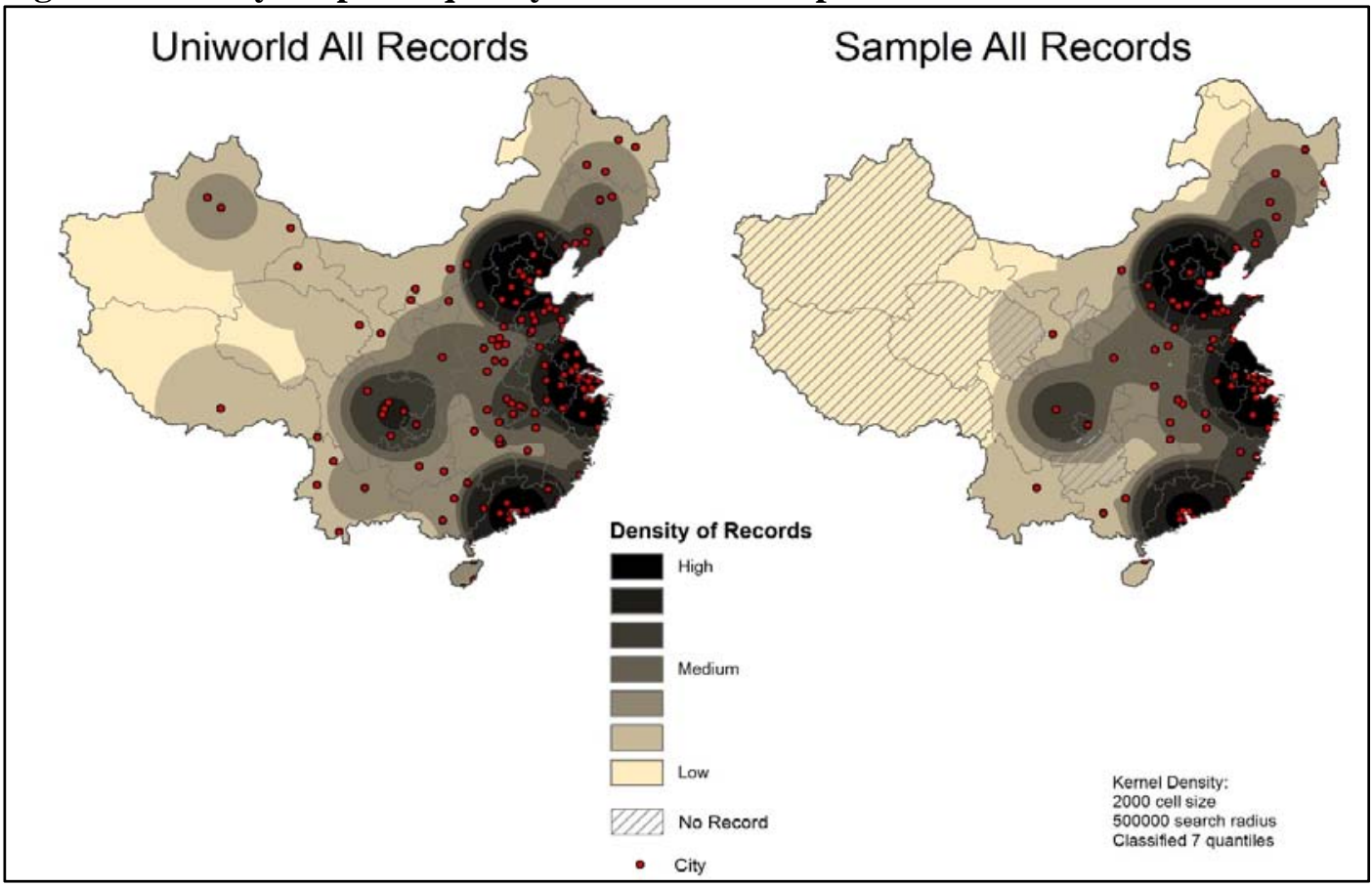


Figure 3. U.S. FDI Frequency and Total FDI Flows in China for Three Periods: Early (1980-1992), Middle (1993-1999), and Late (2000-2005).

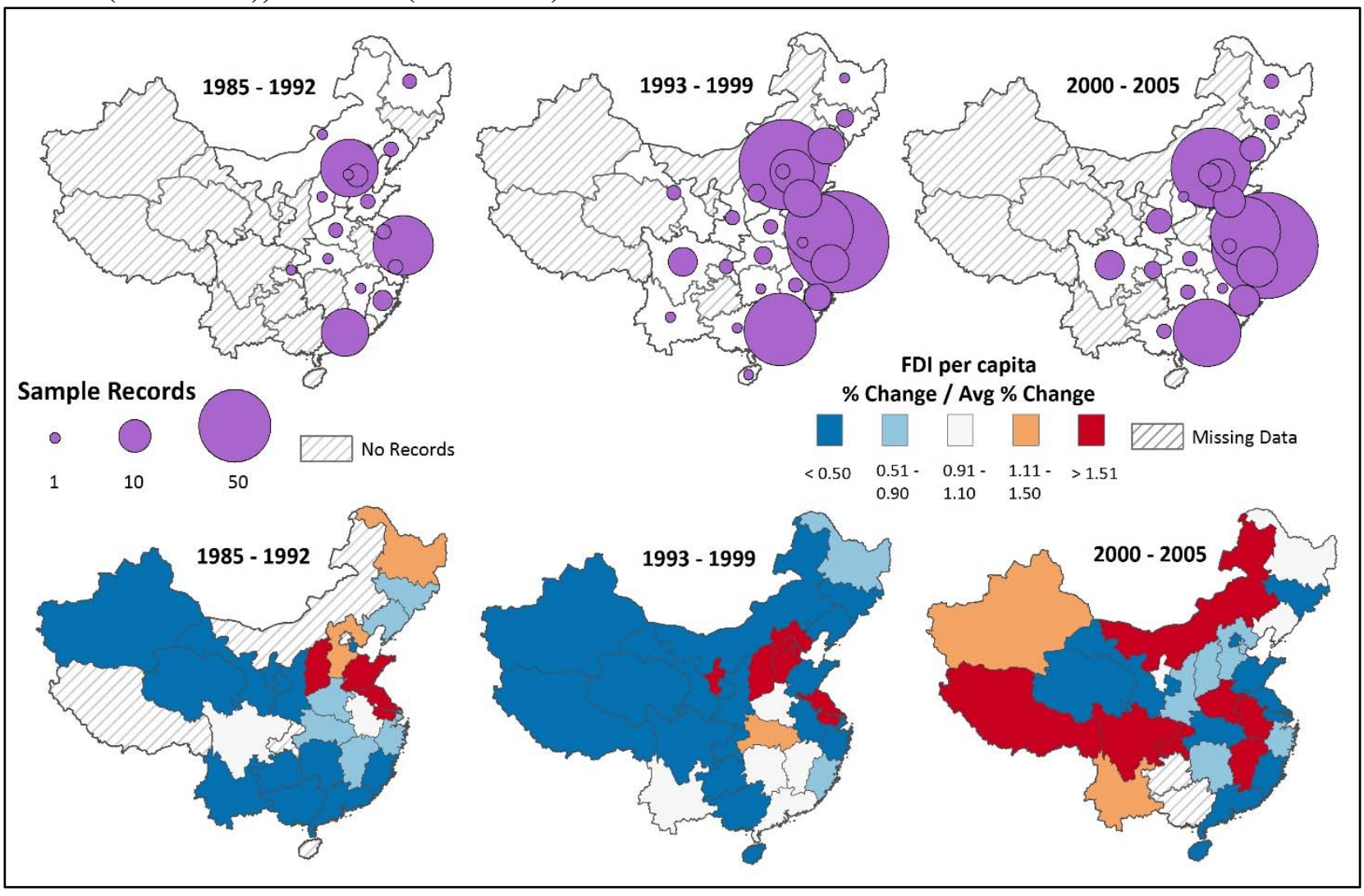

Figure 4: Frequency of Expansion by U.S. Companies in China by Economic Sector.

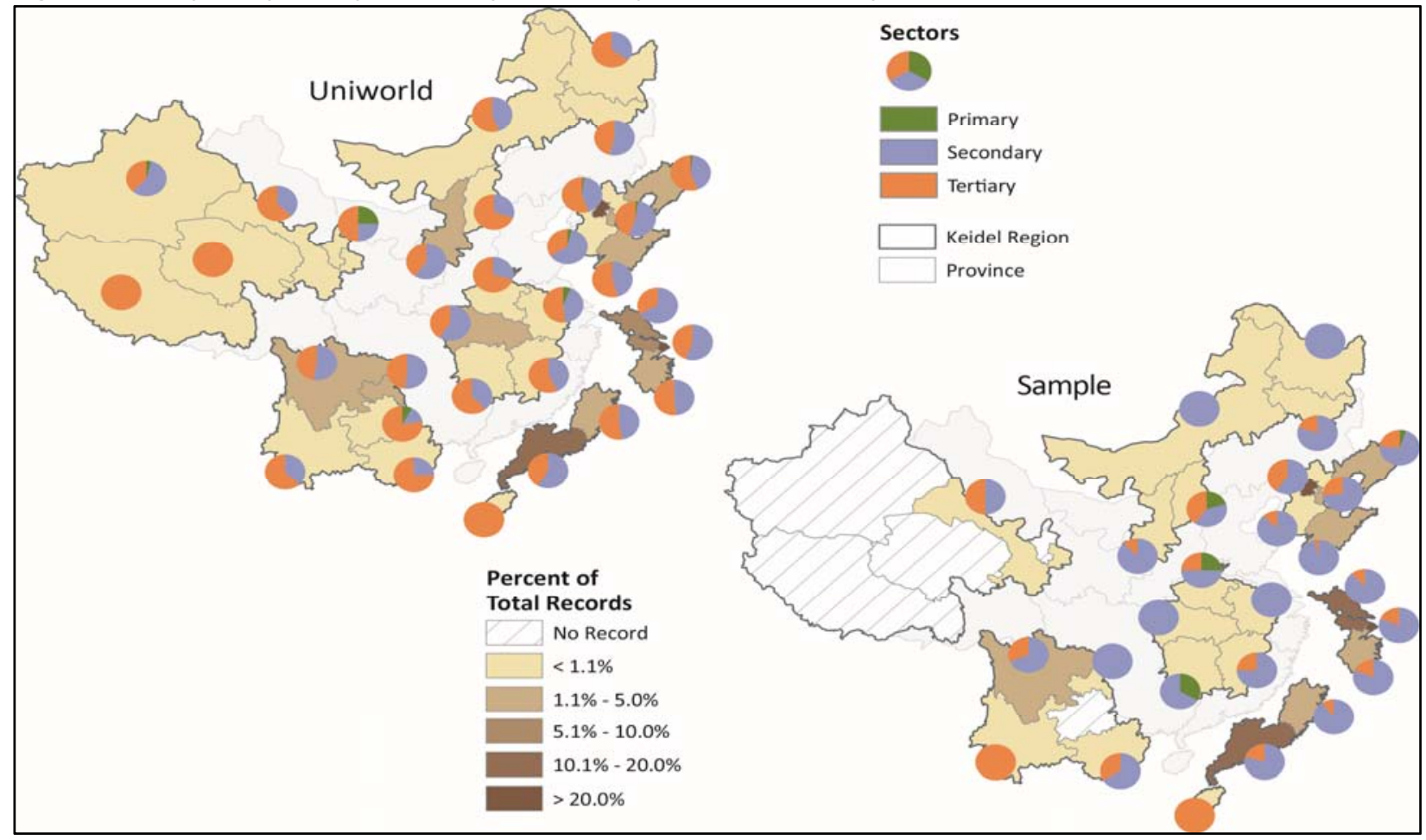


Figure 5. Changes in Province-Level GDP per Capita between 1980 and 2005

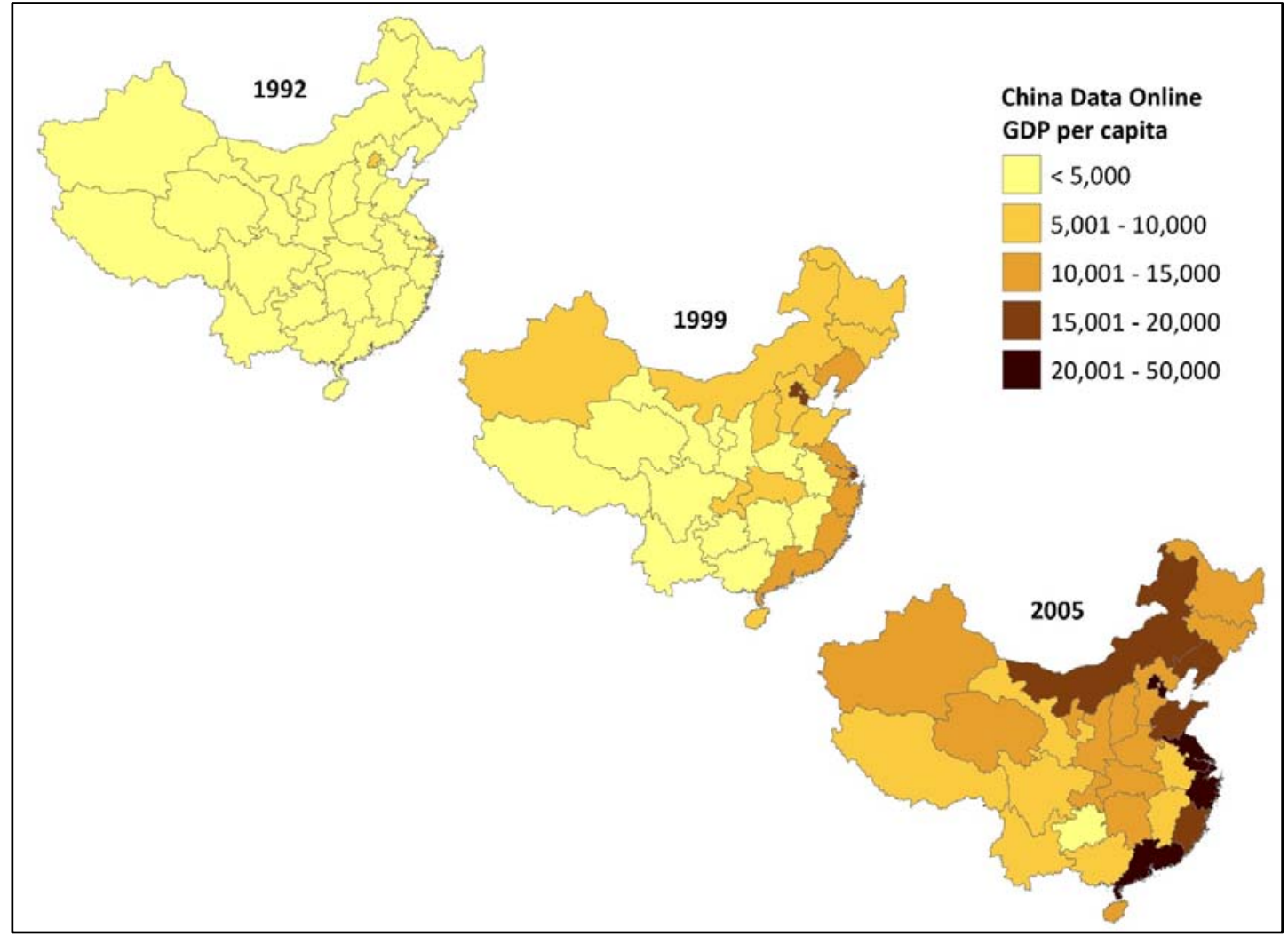

Figure 6. Changes in Province-Level Wages per Capita between 1980 and 2005

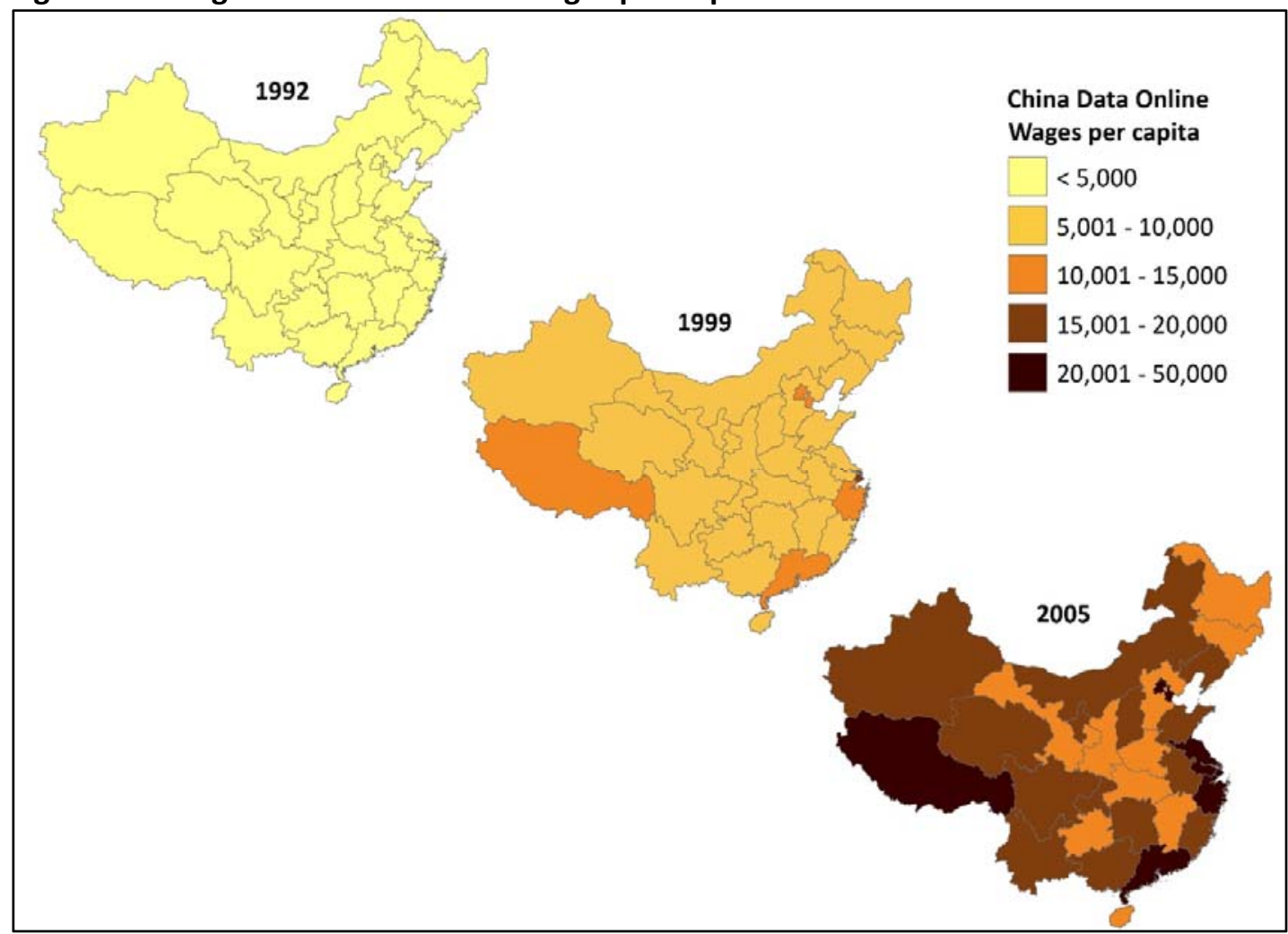


Figure 7. Changes in Province-Level Density of Road and Rail Lines between 1980 and 2005

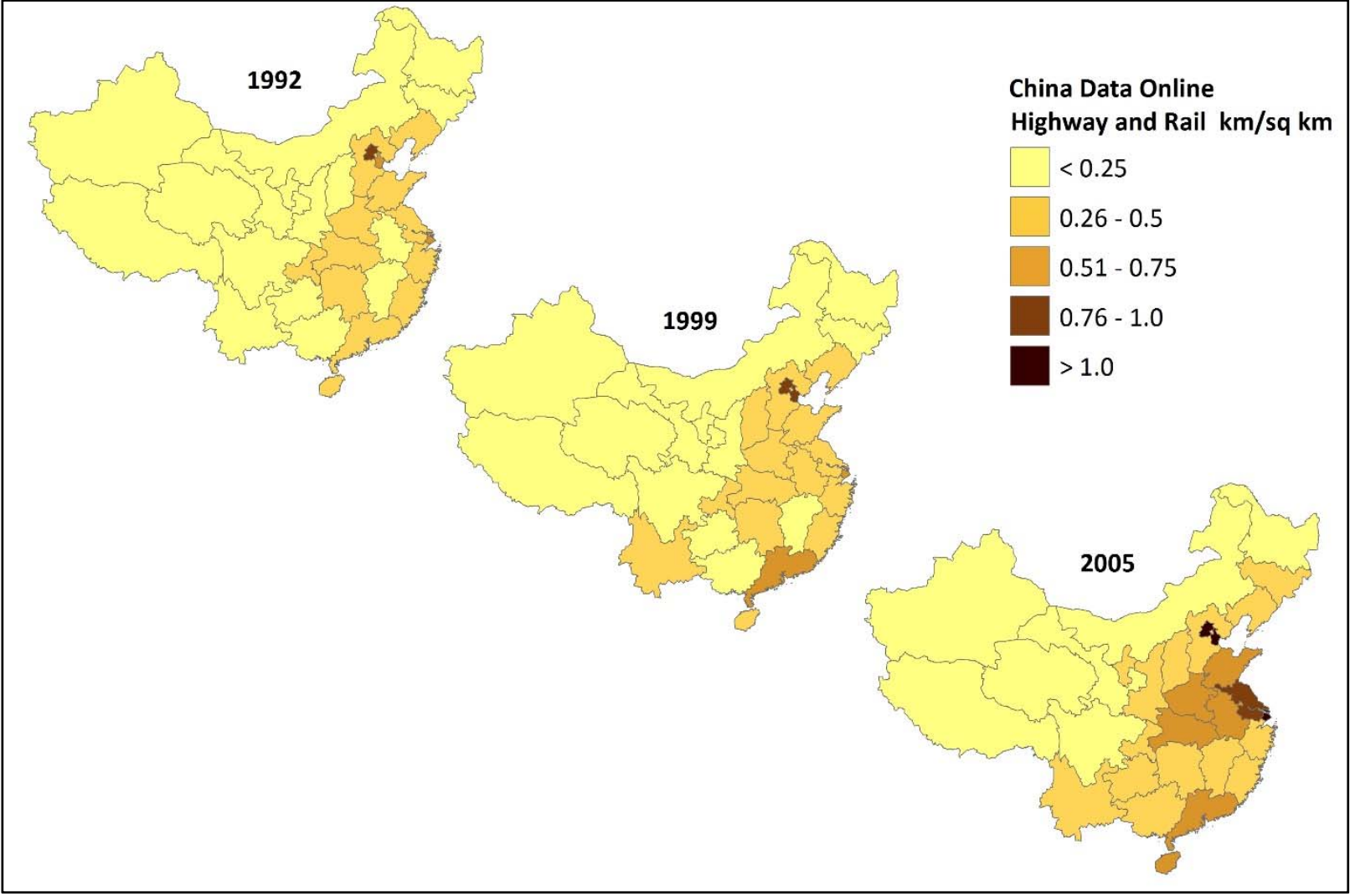


Figure 8. FDI per Capita: Associations with GDP per Capita and Wages per Capita in Early Period (1985-1992) and Middle Period (1993-1999).

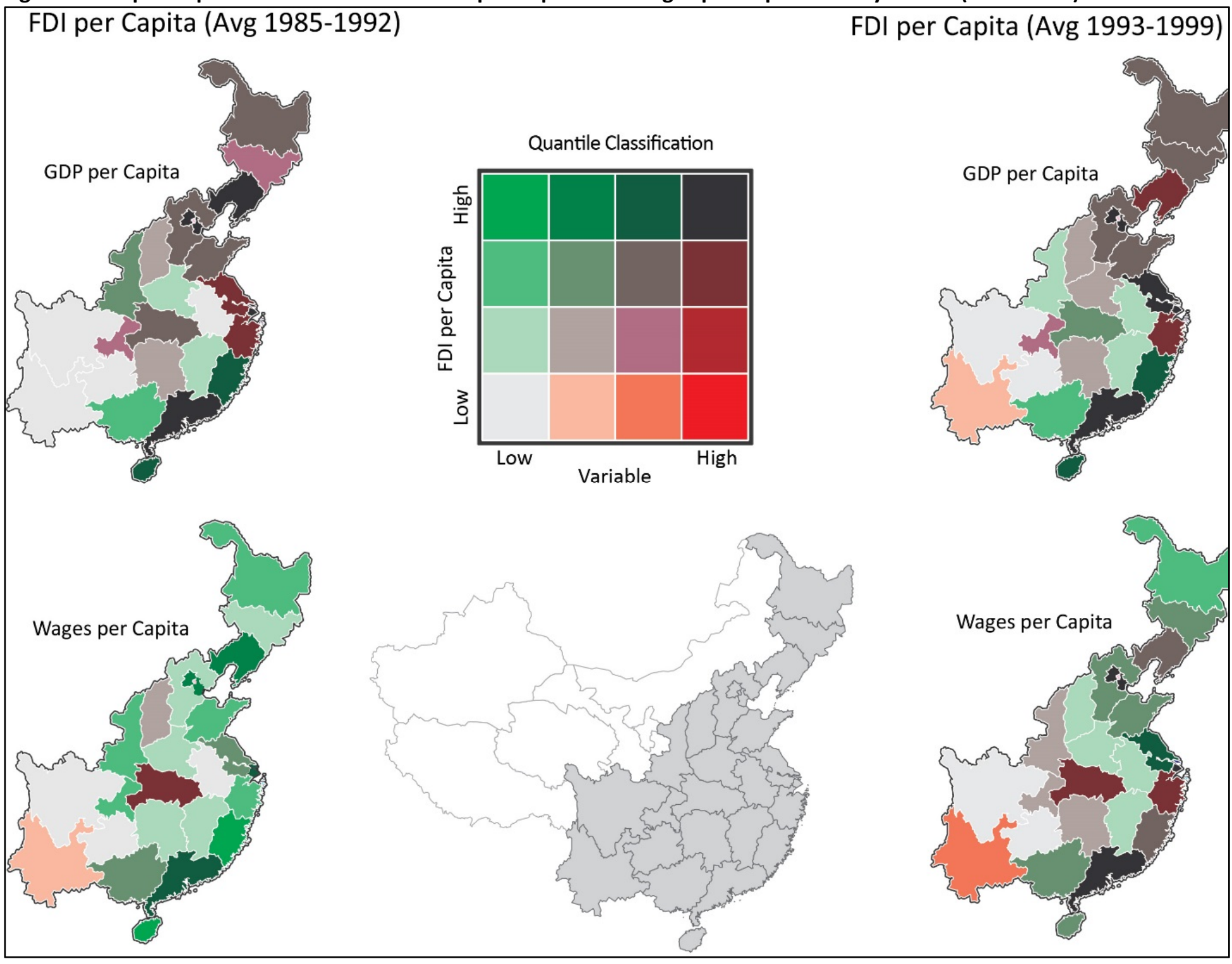


Figure 9. FDI per Capita and its Association with GDP per Capita and Wages per Capita in Middle and (1993-1999) and Late Period (20002005).

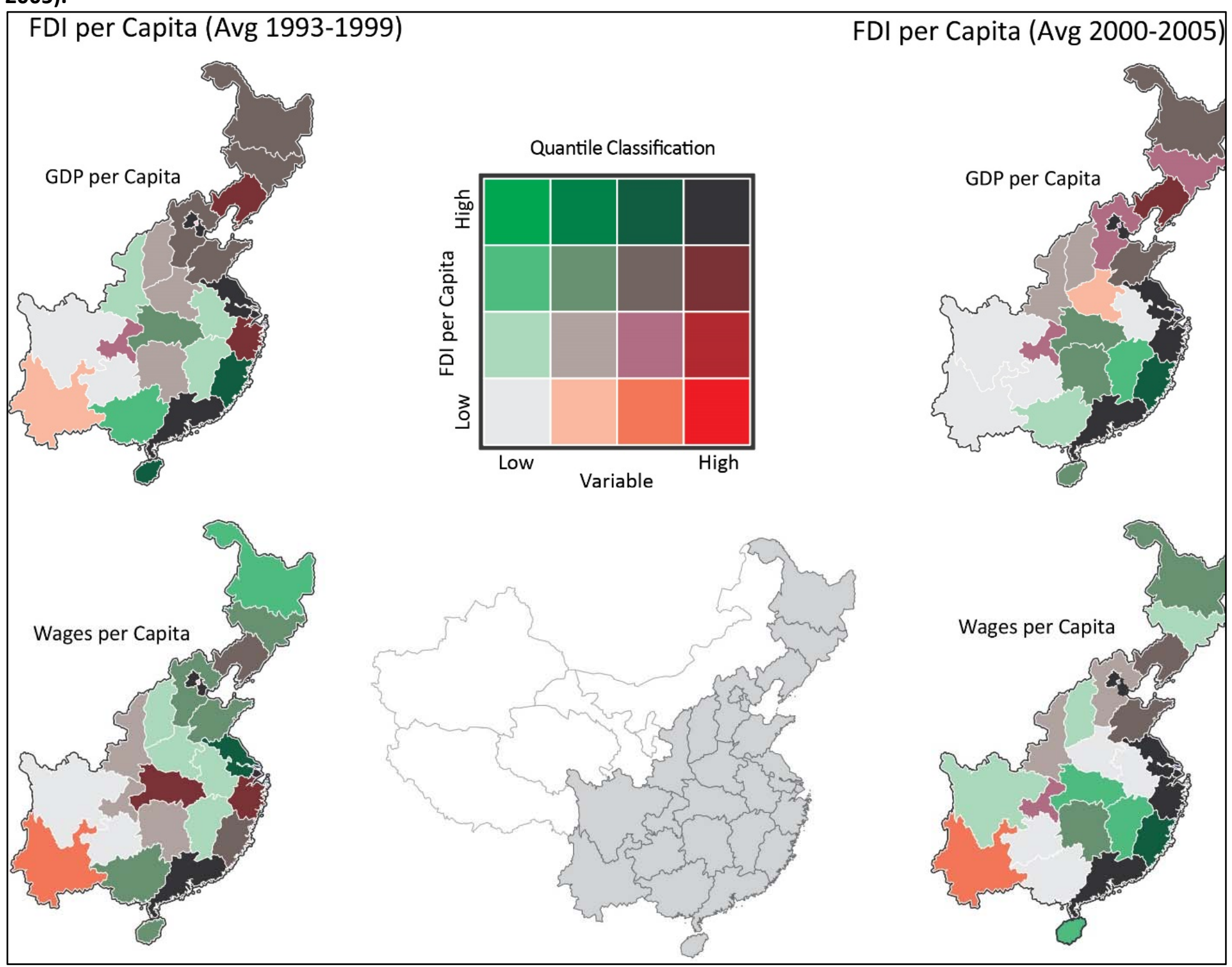


Figure 10. FDI per Capita and its Association with Transportation (Rail and Road Density) as a Measure of Infrastructure for Early (1985-1992), Middle (1993-1999) and Late Period (2000- 2005).

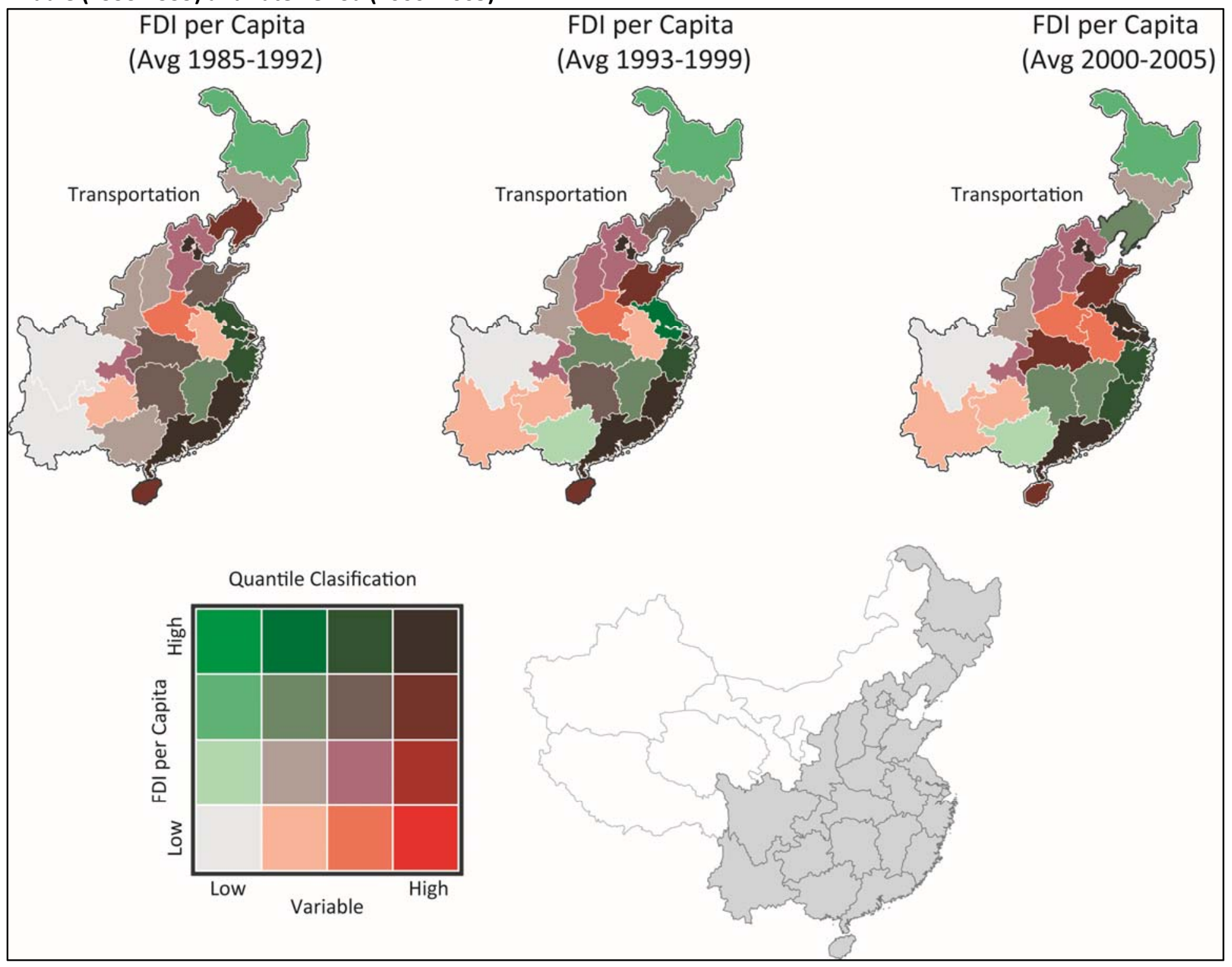

